\title{
History and philosophy of infinity
}

\section{Selected papers from the conference "Foundations of the Formal Sciences VIII" held at Corpus Christi College, Cambridge, England, 20-23 September 2013}

\author{
Brendan P. Larvor ${ }^{1}$ • Benedikt Löwe $\mathrm{e}^{2,3,4}$. \\ Dirk Schlimm 5
}

Received: 28 July 2015 / Accepted: 31 July 2015 / Published online: 29 August 2015

(C) Springer Science+Business Media Dordrecht 2015

The concept of infinity has fascinated philosophers and mathematicians for many centuries: e.g., the distinction between the potential and actual infinite appears in Aristotle's Physics (in his treatment of the paradoxes of Zeno) and the notion was implied in the attempts to sharpen the method of approximation (starting as early as Archimedes and running through the middle ages and into the nineteenth century). Modern mathematics opened the doors to the wealth of the realm of the infinities by means of the set-theoretic foundations of mathematics.

Any philosophical interaction with concepts of infinite must have at least two aspects: first, an inclusive examination of the various branches and applications, across the various periods; but second, it must proceed in the critical light of mathematical results, including results from meta-mathematics.

The conference Foundations of the Formal Sciences VIII: History \& Philosophy of Infinity emphasized philosophical, empirical and historical approaches:

1. In the philosophical approach, questions about the concept of infinity are linked to other parts of the philosophical discourse, such as ontology and epistemology and other important aspects of philosophy of mathematics. Which types of infinity

$凶$ Benedikt Löwe

b.loewe@uva.nl

1 Philosophy, School of Humanities, University of Hertfordshire, Hatfield, Hertfordshire AL10 9AB, UK

2 Institute for Logic, Language and Computation, Universiteit van Amsterdam, Postbus 94242, 1090 GE Amsterdam, The Netherlands

3 Fachbereich Mathematik, Universität Hamburg, Bundesstraße 55, 20146 Hamburg, Germany

4 Corpus Christi College, University of Cambridge, Trumpington Street, Cambridge CB2 1RH, UK

5 Department of Philosophy, McGill University, 855 Sherbrooke St. W., Montreal, QC H3A 2T7, Canada 
exist? What does it mean to make such a statement? How do we reason about infinite entities? How do the mathematical developments shed light on the philosophical issues and how do the philosophical issues influence the mathematical developments?

2. Various empirical sciences deal with the way we as finite human beings access mathematical objects or concepts. Research from mathematics education, sociology of mathematics and cognitive science is highly relevant here. How do we represent infinite objects by finite means? How are infinite objects represented in the human mind? How much is our interaction with infinite concepts formed by the research community? How do we teach the manipulation of infinite objects or processes?

3. Infinity was an important concept in philosophy and theology from the ancient Greeks through the middle ages into the modern period. How did the concepts of infinity evolve? How did questions get sharpened and certain aspects got distinguished in the philosophical debate? Did important aspects get lost along the way?

\section{The FotFS conference series}

The conference was the eighth in the conference series on the "Foundations of the Formal Sciences" (FotFS), a series of interdisciplinary conferences in mathematics, philosophy, computer science, and linguistics. When the conference series started in 1999 as a small German workshop (funded by the Studienstiftung des deutschen Volkes) in Berlin, its main goal was "to provide a platform for young researchers in the different formal sciences to meet [and] to present general ideas, techniques and open questions that lie on the borders between the areas" (Löwe 2002, p. 9). The proceedings of the first conference in the series were published as a special issue of the journal Synthese (Löwe and Rudolph 2002), and we consider it very fitting that we are returning to our roots with this special issue publication.

The defining features of FotFS conferences were present from the very first meeting onwards: a strong interdisciplinary spirit, a focus on technical talks that nevertheless reach out to researchers from other communities, and a (non-exclusive) focus on young researchers.

After its inaugural meeting in Berlin in 1999, FotFS was funded by various sources (e. g., FotFS II was a "PhD EuroConference" funded by the European Commission). Each of the meetings has a distinctive topic specifying some part of the foundations of formal sciences to be investigated in an interdisciplinary way. FotFS II (2001) dealt with Applications of Mathematical Logic in Philosophy and Linguistics (Löwe et al. 2003), FotFS III (2001) with "Complexity in Mathematics and Computer Science" (Löwe et al. 2004), and FotFS IV (2003) was a meta-conference discussing the topic of the series under the heading "The History of the Concept of the Formal Sciences" (Löwe et al. 2006). The conference FotFS V (2004) on "Infinite Games" was held in Bonn (Bold et al. 2007), FotFS VI (2007) on "Reasoning about Probabilities and Probabilistic Reasoning" was held in Amsterdam (Löwe et al. 2009), and the immediate predecessor of our conference, FotFS VII (2008) was held in Brussels under 
the title "Bringing together Philosophy and Sociology of Science" (François et al. 2011).

\section{FotFS VIII: history and philosophy of infinity}

Foundations of the Formal Sciences VIII (FotFS VIII) took place from 20 to 22 September 2013 at Corpus Christi College, Cambridge, England. The conference was organized by the network INFTY-New Frontiers of Infinity. Mathematical, Philosophical, and Computational Prospects funded by the European Science Foundation (2009-2014). The main objective of the INFTY network was to stimulate the exchange of ideas among researchers pursuing mathematical, philosophical, and computational approaches to infinity, with a very strong focus on the mathematical approaches. FotFS VIII formed an important event in the lifetime of the network since it linked the predominantly mathematical network members with the philosophical and historical communities.

The Scientific and Organizing Committee of FotFS VIII consisted of Brendan Larvor (Hatfield, U.K.), Benedikt Löwe (chair; Amsterdam, The Netherlands \& Hamburg, Germany), Peter Koellner (Cambridge MA, U.S.A.), and Dirk Schlimm (Montréal, Canada).

\section{Acknowledgments}

The main source of funding of the conference FotFS VIII was the European Science Foundation via the network INFTY-New Frontiers of Infinity. Mathematical, Philosophical, and Computational Prospects. We received additional funding from the Division of Logic, Methodology and Philosophy of Science of the International Union of History and Philosophy of Science (DLMPS/IUHPS) and from the Analysis Trust for student grants.

We should like to thank the staff of Corpus Christi College, Cambridge, for their help in preparing and running the conference: the catering and event staff for arranging the rooms and booking system, the porters for helping our participants to arrive in Cambridge (and noticing that not only Cambridge dons can be eccentric), and the butlers for providing us with food and drink throughout the conference; in particular, we'd like to thank Karolina Kowalczyk for her indefatigable commitment to making the conference a success. The conference participants were welcomed by the President of Corpus Christi College, Dr. Richard McMahon, and the conference dinner in the Hall of the college was presided over by the Reverend James Buxton, Dean of Chapel of Corpus Christi College.

We were asked by the Editors-in-Chief of the journal Synthese whether we would be interested in publishing the refereed proceedings of the conference in their journal and were very happy to accept this invitation-as mentioned, in particular, since the proceedings of the very first conference in the series had been published as a special issue of this journal (see above). The Synthese Editor-in-Chief responsible for our project was Wiebe van der Hoek who supported the process with advice and feedback for which we are very grateful. We invited all speakers at the conference 
to submit journal versions of their talks and received nineteen submissions. These papers were reviewed according to the high standards of the journal Synthese with at least two independent expert referees reading each paper and acceptance requiring positive feedback from both referees; we should like to thank all involved referees for their great (and unremunerated) work. Out of nineteen submissions, the eight papers included in this issue were accepted: of these, four papers are about the history of infinity (Nawar's paper on Aristotle, Uckelman's paper on categorematic and syncategorematic infinity in medieval logic, Cortese's paper on Pascal, and De Bianchi's paper on Kant) and four are about current philosophy of infinity (Incurvati's paper in finitism, Rin's paper on the iterative conception of set, the paper by Antos, Friedman, Honzik, and Ternullo on multiverse conceptions in set theory, and Pantsar's paper on the "process $\rightarrow$ object metaphor" in the creation of infinity). The papers reflect the scope of the conference and its balance between historical and philosophical subjects.

\section{Scheduled talks at FotFS VIII}

The following list documents all talks invited or accepted for presentation at FotFS VIII (including those that had to be cancelled due to various reasons):

Invited speakers

Haim Gaifman. Infinity and the passage from the epistemic to the ontological Catherine Goldstein. This side of infinity

Luca Incurvati. Finitism and open-texture

Matthew Inglis. Reading about cardinality

John Mason. The role of the as-yet-specified as a bridge between unfolding \& completed infinity in teaching \& learning mathematics

Charles Parsons. Infinity and a critical view of logic

Michael Potter. Making sense of potential infinity

Adriane Rini. Aristotle on Thomson's lamp

Christian Tapp. Infinity in Aquinas

Dina Tirosh and Pessia Tsamir. Teaching and learning about infinity: The case of infinite sets

Jean Paul Van Bendegem. A true(r) history of strict finitism

\section{Contributed talks}

Carolin Antos, Sy-David Friedman, Radek Honzik, Claudio Ternullo. Multiverse conceptions and the hyperuniverse programme

Murtaza Chopra. The musical inspiration of procedures involving infinite in Nicole Oresme's Treaties of Configurations

João Cortese. The Pascalian notion of infinity-What does "infinite distance" mean?

Silvia De Bianchi. When series go in indefinitum, ad infinitum and in infinitum. Concepts of infinity in Kant's philosophy and cosmology 
Susan Edwards-Mckie: Wittgenstein, Einstein and Leibniz: "Härte des logischen Zwangs" and "Unendliche Möglichkeit". Some remarks arising from Wittgenstein's "Cosmic Fragment"

Philip Ehrlich. Cantorian and non-Cantorian theories of finite, infinite and infinitesimal numbers and the unification thereof

Marco Forti. How to measure the size of sets. Aristotle-Euclid or Cantor-Zermelo?

Pieter Sjoerd Hasper. Aristotle on infinity

Ramzi Kebaili. Poincaré and Brouwer on infinity

Peter Koepke. Embedding uncountable cardinality techniques into the realm of countable sets

Yoshihiro Maruyama. Continuous vs. discrete infinity in the foundations of mathematics and physics

Christopher Menzel. Modal realism and the absolute infinite

Françoise Monnoyeur-Broitman. Nicholas of Cusa's methodology of the infinite

Tamer Nawar. An Aristotelian approach to infinite causal sequences

Andrew Nicholson. Plenitudinous platonism, the multiverse of sets and infinity

Markus Pantsar. In search of $\aleph_{0}-$ How infinity can be created

Matthew Parker. Gödel's argument for Cantor's cardinals

Helmut Pulte. "Understanding the World from the infinitely small": Bernhard Riemann's philosophy of geometry and science in context

Erich Reck. On Dedekind's explanation of the finite in terms of the infinite

Benjamin Rin. Infinity and recursion

Sam Sanders. The ghosts of departed quantities as the soul of computation

Norman Sieroka. Anaximander's notion of the "apeiron"-A forerunner of the modern concept of infinity?

Henrik Kragh Sørensen. Infinity and intuition in analysis between Euler and Weierstra $\beta$

Monica Solomon. The case of infinite series: Wallis and Newton

Gabriel Tarziu. Infinities in science

Sara L. Uckelman The logic of categorematic and syncategorematic infinity

John Wigglesworth. Modal set theory

Sean Winkler. Being of essence, being of existence: Spinoza and the finite

\section{The conference photo}

The conference photo was taken by Sara Uckelman in the Bursar's Garden of Corpus Christi College in front of the windows of William Wilkins's 19th century chapel. 


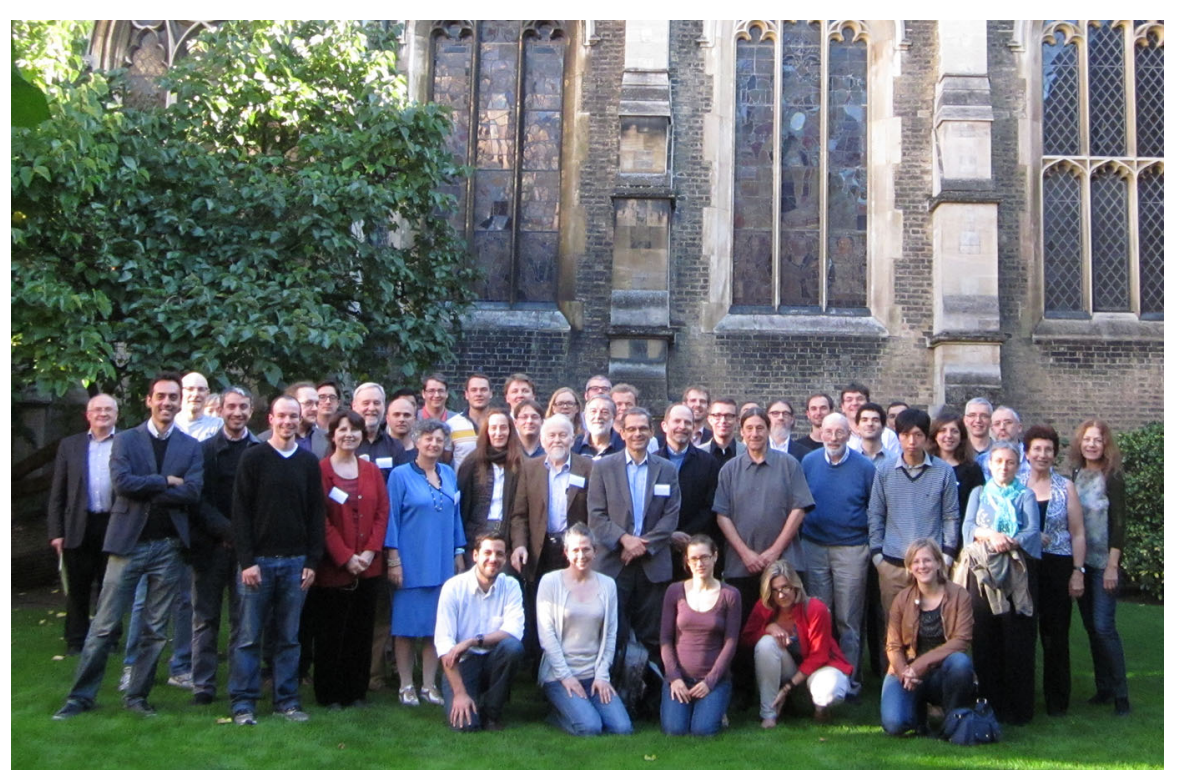

\section{References}

Bold, S., Löwe, B., Räsch, T., \& van Benthem, J. (Eds.). (2007). Foundations of the Formal Sciences V, Infinite Games. Vol. 11 of Studies in Logic. London: College Publications.

François, K., Löwe, B., Müller, T., \& Van Kerkhove, B. (Eds.). (2011). Foundations of the Formal Sciences VII, Bringing Together Philosophy and Sociology of Science. Vol. 32 of Studies in Logic. London: College Publications.

Löwe, B. (2002). The formal sciences: Their scope, their foundations, and their unity. Synthese, 133(1-2), $5-11$.

Löwe, B., \& Florian, R. (Eds.). (2002). Foundations of the Formal Sciences I, Humboldt-Universität zu Berlin, May 7-9, 1999. Special issue of Synthese (Volume 133, Number 1-2, October/November 2002).

Löwe, B., Malzkorn, W., \& Räsch, T. (Eds.). (2003). Foundations of the Formal Sciences II, Applications of Mathematical Logic to Philosophy and Linguistics, Papers of a Conference held in Bonn, November 10-13, 2000. Vol. 17 of Trends in Logic. Dordrecht: Kluwer Academic Publishers.

Löwe, B., Pacuit, E., \& Romeijn, J. W. (Eds.). (2009). Foundations of the Formal Sciences VI, Probabilistic Reasoning and Reasoning with Probabilities. Vol. 16 of Studies in Logic. London: College Publications.

Löwe, B., Peckhaus, V., \& Räsch, T. (Eds.). (2006). Foundations of the Formal Sciences IV, The History of the Concept of the Formal Sciences. Vol. 3 of Studies in Logic. London: College Publications.

Löwe, B., Piwinger, B., \& Räsch, T. (Eds.). (2004). Classical and new paradigms of computation and their complexity hierarchies, Papers of the conference "Foundations of the Formal Sciences III" held in Vienna, September 21-24, 2001. Vol. 23 of Trends in Logic. Dordrecht: Kluwer Academic Publishers. 